\title{
DWDM TRANSMISSION BASED ON THE THIN-FILM FILTER TECHNOLOGY
}

\author{
O. Ozoliņš, V. Bobrovs, G. Ivanovs \\ Institute of Telecommunications, Riga Technical University, \\ 12 Āzenes Str., Rīga, LV-1048, LATVIA
}

\begin{abstract}
A dense wavelength division multiplexing (DWDM) transmission scheme with two thin-film filters (FWHM bandwidth $100 \mathrm{GHz}$ and $200 \mathrm{GHz}$ ) has been realized to evaluate the minimum channel interval needed for a satisfactory bit error ratio. For this purpose, detailed research was conducted into the impact of the filters on the optical signal's de-multiplexing in a DWDM system, in which the measurements of eye diagrams and the optical power spectral densities of a received signal were made. From the results of measurements the minimum channel interval has been found for the optical filters that ensures reliable data transmission and higher spectral efficiency of the whole system. It was found that for a DWDM system with a 100 $\mathrm{GHz}$ filter a sufficient channel interval is $75 \mathrm{GHz}$ at $10 \mathrm{Gbit} / \mathrm{s}$ data transmission speed, which means that its spectral efficiency is increased from $0.1 \mathrm{bit} / \mathrm{s} / \mathrm{Hz}$ to $0.1333 \mathrm{bit} / \mathrm{s} / \mathrm{Hz}$.

Key words: dense wavelength division multiplexing (DWDM), thin film filters (TFFs), nonlinear optical effects (NOEs).
\end{abstract}

\section{INTRODUCTION}

The currently employed lightwave systems benefit from increased transmission distance with optical amplification and higher capacity achieved owing to the use of the wavelength division multiplexing (WDM) technology. Emergence of efficient and powerful broadband optical amplifiers - in particular, erbium-doped fibre amplifiers (EDFAs) - has spurred an enormous increase in the capacity and reach in the telecommunication networks. The large gain bandwidth for these amplifiers has enabled dense WDM (DWDM) technology for long enough distances and channel counts [1]. Instead of installing new fibre links, additional wavelength channels are added to the existent transmission systems. These channels operate at fixed optical frequencies (defined by International Telecommunication Union (ITU), G.694.1 recommendation [2]). In particular, DWDM technology provides greater network flexibility, with reduced complexity of the control system. The DWDM is a technology that uses multiple wavelengths to transport the data through a large number of separate channels at high data rates. The reach of existing systems is limited by noise from the used amplifiers, combined with nonlinear effects from transmission [1]. Most of today's optical network concepts are based on DWDM, which means that optical filters are mainly needed in order to route and select specific wavelength channels $[3,4]$.

Thin-film filters (TFFs) have been widely used in a variety of fields [5]. These devices were the first filter type to be widely employed in WDM systems in 
the 1990s. The relevant technology, being relatively mature, was then used for implementation of WDM optical systems. As concerns optical interference coatings, they have been fabricated since 1930 [6]. As the TFF is a low-cost optical component, it has widely been employed in the fibre optic devices for the last 20 years [7]. Apart from enabling the channel separation in $200 \mathrm{GHz}$ and later in $100 \mathrm{GHz}$ DWDM systems, this is realized in a number of optical network applications - such as gain-flattening filters (GFF) for EDFA, wideband splitting filters for separating bands of channels; more recently, this technology has been employed in implementation of low-cost modules for access networks [6].

The research on optical communications in the past years was partly directed towards increasing the total capacity of a single optical fibre. The greatest proportion of these research works are based on different modulation schemes in various combinations [8]. An alternative approach for increasing the transmission capacity is to reduce the channel spacing of a DWDM system to the minimum while keeping the employed optical filter technologies. In this paper, we will restrict our consideration to the TFFs in DWDM transmission systems. We have measured the amplitude transfer functions of TFFs with $100 \mathrm{GHz}$ and $200 \mathrm{GHz}$ full width half maximum (FWHM) bandwidth, and evaluated the minimum channel spacing of $2.5 \mathrm{Gbit} / \mathrm{s}$ and $10 \mathrm{Gbit} / \mathrm{s}$ DWDM systems with amplifiers, containing optical filters of the kind over $40 \mathrm{~km}$ of a standard single mode fibre (SSMF). As is shown below, for the DWDM system with $100 \mathrm{GHz}$ TFF a satisfactory performance is achieved with a $75 \mathrm{GHz}$ channel interval at the $10 \mathrm{Gbit} / \mathrm{s}$ data transmission speed.

\section{THIN-FILM FILTER TECHNOLOGY}

One of the most common passive devices for multiplexing/de-multiplexing (mux/de-mux) of optical signals in the DWDM transmission systems is the thinfilm filter (TFF) due to its design flexibility and technological maturity for achieving low loss, high isolation, and wide bandwidth performances [9]. A TFF can be made to have excellent wavelength stability, which makes this device an appropriate passive component [6]. Particularly, a TFF device is presently in a 1x2 port configuration, when one filter is inserted between a dual-fibre optic collimator and a single-fibre optic collimator [7].

Thin-film filters have been employed for filtering light with a particular wavelength (e.g. colour filters in the visible region) for a long time; the principle of its operation has long been known. However, the passive devices used in DWDM transmission systems are different from the known colour filters in terms of performance requirements, structure, and degree of the process control: for mux/demux of DWDM transmission systems a large bandwidth (more than $50 \%$ of the channel spacing), high transmission percentage (more than 95\%), and high degree of isolation (more than $25 \mathrm{~dB}$ ) are required [9].

A band-pass TFF device consists of one or more coupled thin-film FabryPerot filters. A filter of the kind contains a thin-film etalon (called the spacer layer) surrounded by all-dielectric thin-film reflectors. In a Fabry-Perot filter, only a small portion of light penetrates the first reflector, while at resonant wavelengths the light intensity increases in the spacer layer until a substantial proportion of the input light is transmitted [6]. Mux/de-mux devices for DWDM applications have to 
pass very stringent environmental tests: high humidity, high temperature, and various mechanical tests; the lifetime of such an optical device is expected to be at least 25 years [9].

As shown in Fig. 1, a typical single-cavity layered TFF structure contains reflectors (quarter-wave layers) and a spacer (half-wave layers). All the layers composing the TTF structure are combined of materials with high and low refractive index $[9,10]$. The most commonly used low-index material is $\mathrm{SiO}_{2}$, and as highindex materials $\mathrm{TiO}_{2}$ and $\mathrm{Ta}_{2} \mathrm{O}_{5}$ are typically used because of their high refractive index, low absorption and stability at $1550 \mathrm{~nm}$ [10]. The thickness of the spacer layer determines the central wavelength of a filter, while alternating reflector layers determine its reflectivity [9].

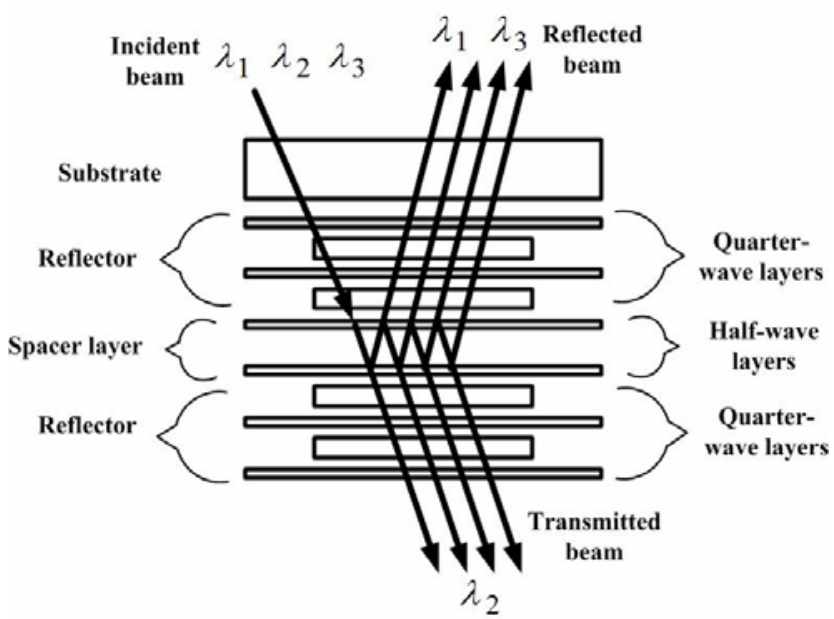

Fig. 1. Structural model of a typical single-cavity TFF $[9,10]$.

A TFF is feasible to employ in modular architectures that start with a few channels but can later be expanded as the need for a greater bandwidth arises. The transmission of a filter at non-resonant wavelengths as well as the pass-band width is determined by the number of periods in the reflectors. As the reflectors are made with higher reflectivity, the transmission at non-resonant wavelengths is suppressed, whereas the resonant transmission is preserved as mentioned above, narrowing the filter [6]. The numbers of layers vary depending on the particular performance requirements. When a light beam with components of different wavelength is launched into the device, portion of the light with the frequency component matching the resonant frequency of the cavity is transmitted, and the rest of the light beam is reflected by the filter. The properties of a single-cavity TFF are similar to those of a single-cavity etalon filter with narrow bandwidth and limited isolation [9].

However, the DWDM systems necessitate wide bandwidth and high isolation due to the signal modulation requirement and central wavelength drift of laser sources [9]. The TFF can be designed and built to have nearly square passband characteristics, which makes them useful as DWDM band-pass filters [6]. It is known that the pass-band of a TFF can be flattened to impart a square shape by cascading multiple spacers in the structure [9]. The familiar square shape of a DWDM filter is achieved by inducing a very strong resonance: the light is trapped 
within the filter for an appreciable time, especially near the band edges, to achieve constructive interference and eventual transmission through the multi-cavity structure [6]. It is clear that better filtering performance can be obtained by increasing spacers in the filter design. However, in practice, this will result in the enlarged number of the layers and additional difficulties in the film deposition; also, the chromatic dispersion (CD) increases linearly with the order of the filter, and quadratically with the bandwidth reduction. Strong CD is a limiting effect in a DWDM transmission system. Different delay for the wavelength components of a pulse can lead to broadening and distortion. To maintain isolation, a filter with higher cavity count may have steeper edges, increasing the CD but still pushing it from the channel centre. Another approach is to give up some of the filter "squareness", trading the transmission penalty for that of chromatic dispersion $[6,9]$.

\section{SCHEME FOR MEASURING THE AMPLITUDE TRANSFER FUNCTION OF AN OPTICAL BAND-PASS FILTER}

Performance of the mux/de-mux is far from full capacity in the field applications. The best approach for fault elimination when adding new channels is to define spectral properties of a system's passive components [11].

(a)

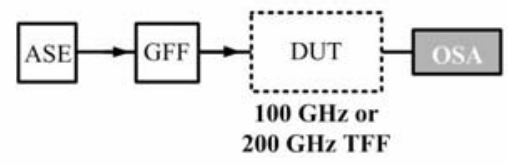

(b)

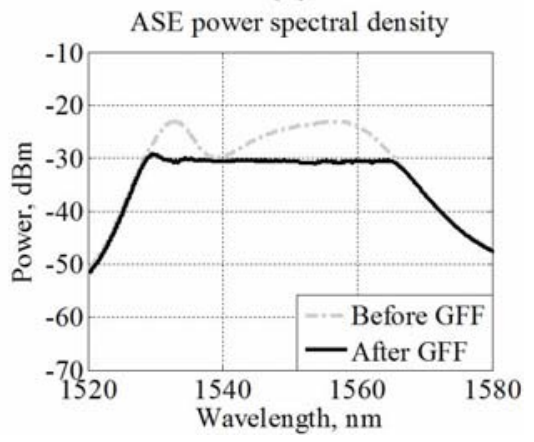

Fig. 2. (a) Optical band-pass filter's block-diagram of amplitude transfer function measurements;

(b) Spectral density curve of the ASE light source power (for notes see the text).

Two methods can be employed to perform measurements of the amplitude transfer function of a passive device. In the former, a tunable laser source and a power meter are used, with sweeping through the passive device, while in the latter - a broadband source and an optical spectrum analyser (OSA) to perform the sweeping. The second method is better for testing such passive devices as filters and other high-loss optical components [11].

In particular, the second method was used to obtain the amplitude transfer functions of TFFs with $100 \mathrm{GHz}$ and $200 \mathrm{GHz}$ FWHM bandwidth. The measurement circuit (for its block diagram see Fig. 2) consists of an amplified spontaneous emission (ASE) light source, gain flattening filters (GFFs), the device 
under test (DUT) - a $100 \mathrm{GHz}$ or a $200 \mathrm{GHz}$ TFF, and the ADVANTEST Q8384 optical spectrum analyser (OSA). This type of light source is created by combining a light emitting diode ( $975 \mathrm{~nm}$ central wavelength) with a $10 \mathrm{~m}$ long erbium-doped fibre. The ASE power spectral density lies in the wavelength range from $1530 \mathrm{~nm}$ to $1565 \mathrm{~nm}$ and is flattened with GFF to reduce the amplitude variations in the measured power spectral densities (Fig. 2b). Such an ASE source together with an OSA can be used for determination of the amplitude transfer function of passive optical components.

(a)

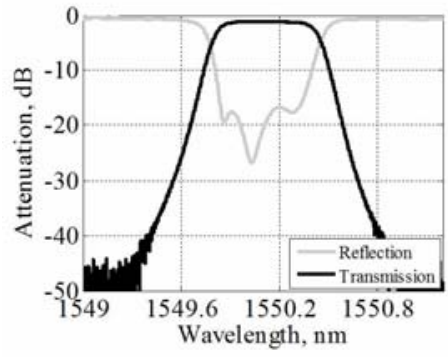

(b)

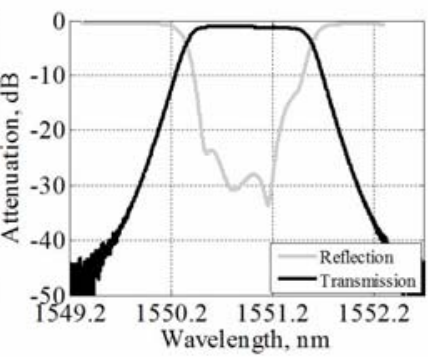

Fig. 3. The measured functions of amplitude transfer in reflection and transmission of the TFF with (a) $100 \mathrm{GHz}$ FWHM bandwidth, (b) $200 \mathrm{GHz}$ FWHM bandwidth.

Figure 3 shows the measured amplitude transfer functions in the transmission and reflection of two TFFs under consideration. The central wavelength, bandwidth, adjacent channel isolation, and insertion loss of a passive optical device is estimated from the measured amplitude transfer functions. The TFFs $(100 \mathrm{GHz}$ and $200 \mathrm{GHz}$ FWHM bandwidth) were produced for the $33^{\text {rd }}(1550.92 \mathrm{~nm}$ or $193.3 \mathrm{THz})$ and the $34^{\text {th }}(1550.12$ or $193.4 \mathrm{THz})$ channels of the ITU-T frequency grid, accordingly.

\section{MEASUREMENT RESULTS AND DISCUSSION}

The realization of the most efficient data transmission via optical systems is also dependent on the optical band-pass filter performance. Therefore, detailed research into the TFF influence on the optical signals in DWDM has been done. The DWDM transmission scheme with two TFFs (100 GHz and $200 \mathrm{GHz}$ FWHM bandwidth) was worked out to evaluate the minimal channel interval at which the bit error ratio (BER) is sufficiently low $\left(<10^{-12}\right)$. The evaluation was performed using eye diagrams and measured optical power spectral densities of the received signal.

The realized DWDM transmission scheme has two channels and consists of three parts: a transmitter, an optical fibre, and a receiver. In turn, the transmitter (Fig. 4) consists of a pseudo-random data source with $2^{31}-1$ bit sequence (Anritsu MU181020A), a non-return-to-zero (NRZ) code former (Anritsu MU181020A), a tunable continuous wavelength (CW) laser source (Agilent 81989A, 81949A), and an Avanex $\mathrm{LiNbO}_{3}$-based external Mach Zehnder's modulator (MZM). The data source produces a pseudo-random electrical signal which contains the information to be transmitted via optical fibre. Then a code former is used to form an NRZ code from the incoming pseudo-random bit sequence. This code format has long been 
dominant in the fibre optics transmission systems, because of relatively low electrical bandwidth for transmitters and receivers and insensitivity to the laser phase noise [3]. The optical pulses are obtained by modulating CW laser irradiation in MZM with the previously mentioned bit sequence. After optical modulation, the optical pulses are amplified in optical amplifier (Keopsys KPS-BT2-C-HPFB) so that they can be transmitted for moderate distances. The erbium-doped fibre amplifier is used to ensure the optical amplification and the output level of the signal is set to $17 \mathrm{dBm}$. After that, the formed optical pulses are sent directly to a $40 \mathrm{~km}$ SSMF (G.652.d). The utilized fibre has a large core effective area of $80 \mu \mathrm{m}^{2}$, attenuation $\alpha=0.2 \mathrm{~dB} / \mathrm{km}$, nonlinear refractive coefficient $n_{k}=2.5 \cdot 10^{-20} \mathrm{~cm} / \mathrm{W}$, and dispersion $16 \mathrm{ps} / \mathrm{nm} / \mathrm{km}$ at the reference wavelength $\lambda=1550 \mathrm{~nm}$. The receiver block consists of an optical filter (100 GHz or $200 \mathrm{GHz}$ TFF), a PIN photodiode, and a Bessel-Thomson's electrical filter (4 poles, $7.5 \mathrm{GHz}-3 \mathrm{~dB}$ bandwidth, Anritsu MP1026A) [12].

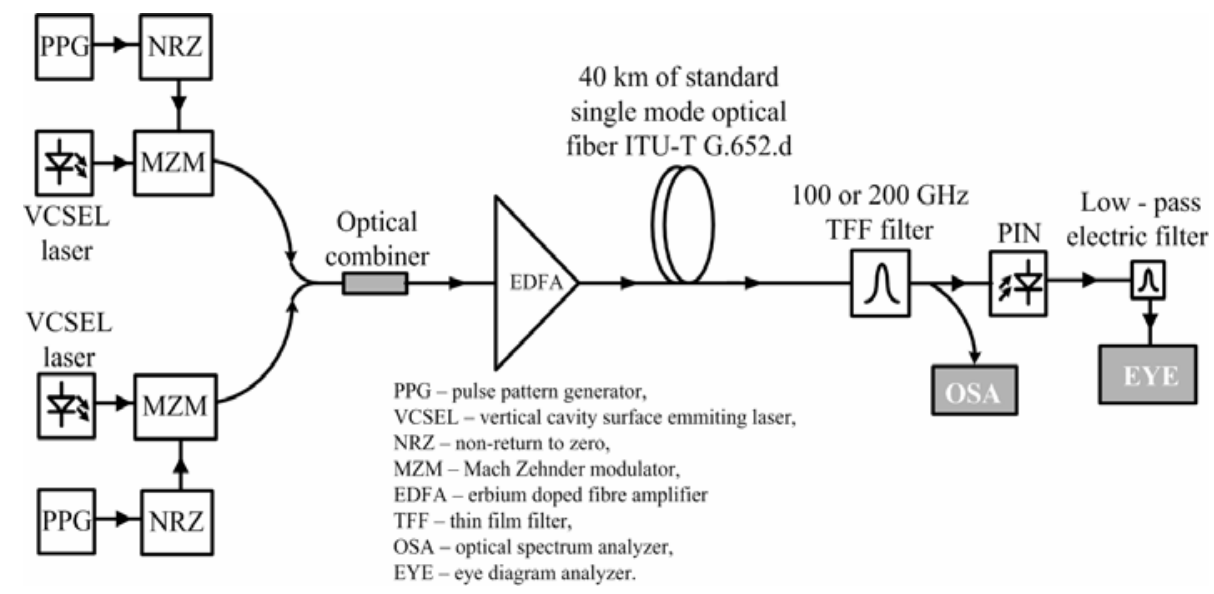

Fig. 4. Two-channel DWDM measurement circuit.

In this research we have measured the eye diagrams and optical power spectrum densities to determine the minimal channel interval for DWDM systems with $100 \mathrm{GHz}$ and $200 \mathrm{GHz}$ TFFs. A high-frequency oscilloscope was used to perform the eye diagram measurements, and the optical spectrum analyser was employed to obtain consistent spectral densities of the optical power.

The BER evaluation is a straightforward and simple method for performance estimation based on counting the errors in the received bit streams. The error counting in a practical system with a transmission speed greater than $1 \mathrm{Gbit} / \mathrm{s}$ can be a long process, especially for realistically low BER values $\left(<10^{-12}\right)$. Therefore the ITU has created the eye diagram masks for different bit rates with a definite BER value. The spectral density of optical power is a widely used criterion for evaluation of the system performance in already deployed transmission lines. The optical noise from transmission media and devices around an optical signal reduces the receiver's ability to correctly detect the signal. This effect can be suppressed placing the optical filter before the optical receiver. Nowadays, a modern OSA can perform such measurements automatically, simultaneously for the optical power spectral densities and the optical signal-to-noise ratio [12]. 


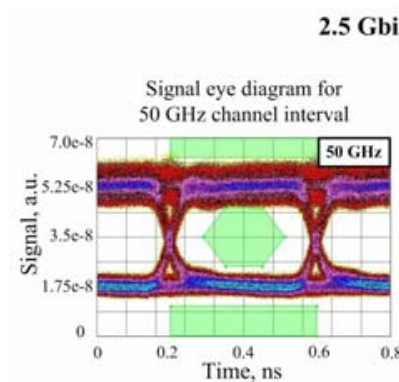

(a)

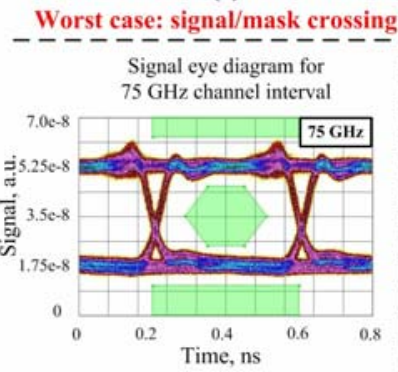

(b)

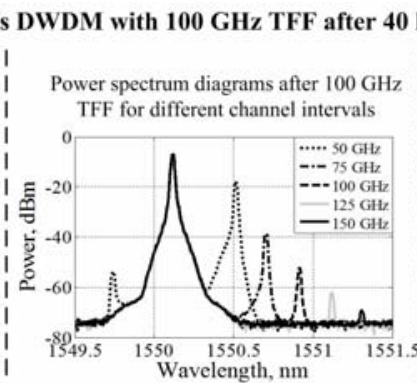

(f)

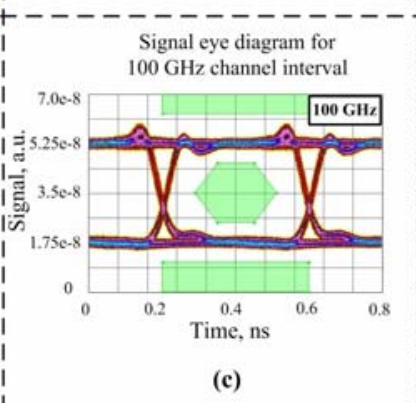

Signal eye diagram for $150 \mathrm{GHz}$ channel interval

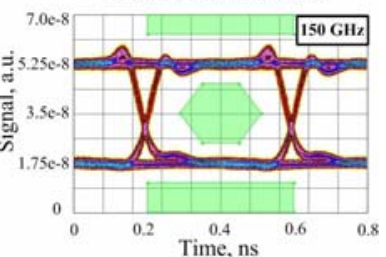

(e)

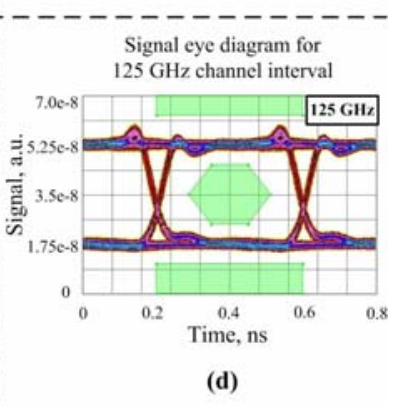

Fig. 5. Eye diagrams $(a-e)$ and optical power spectral densities $(f)$ of $2.5 \mathrm{Gbit} / \mathrm{s}$ DWDM system realized with a $100 \mathrm{GHz}$ TFF after $40 \mathrm{~km}$ of SSMF for different channel intervals (shown in insets).

Figure 5 shows the eye diagrams and optical power spectral densities of a $2.5 \mathrm{Gbit} / \mathrm{s}$ DWDM system $100 \mathrm{GHz}$ TFF (whose amplitude transfer function is shown in Fig. $3 a$ ) after $40 \mathrm{~km}$ of SSMF for different channel intervals from $50 \mathrm{GHz}$ to $150 \mathrm{GHz}$ with $25 \mathrm{GHz}(0.2 \mathrm{~nm}$ in a wavelength range) step. The step value was chosen to fit DWDM system channels to the wavelength grid defined in ITU-T G.694.1 recommendation. Nonlinear interaction in the $2.5 \mathrm{Gbit} / \mathrm{s}$ DWDM system, $100 \mathrm{GHz}$ TFF, was observed with a $50 \mathrm{GHz}$ channel interval. This nonlinearity is presented as a new frequency component generated by nonlinear optical effects (NOEs). To reduce undesirable nonlinear interaction between adjacent signals, the channel interval was increased, which gave lower BER values for the detected signal. As a result, the adjacent channel was suppressed more efficiently, because the steepness of a $100 \mathrm{GHz}$ TFF device is very good and the adjacent channel's isolation is approx. $40 \mathrm{~dB}$. As can be seen from the results (Fig. $5 b$ ), a $75 \mathrm{GHz}$ channel interval is sufficient to ensure the appropriate BER value for adequate system's performance. The results for greater channel intervals $(100 \mathrm{GHz}, 125 \mathrm{GHz}$ and $150 \mathrm{GHz}$, Fig. 5c-e) are also shown to demonstrate DWDM (100 GHz TFF) system's stability in the spectral range employed for transmission.

The eye diagrams and optical power spectral densities of a $10 \mathrm{Gbit} / \mathrm{s}$ DWDM system (100 GHz TFF) after $40 \mathrm{~km}$ of SSMF for the same channel intervals as in the previous case are shown in Fig. 6. Similar to the above, a $75 \mathrm{GHz}$ channel interval is sufficient to ensure the appropriate BER value for normal performance of the system at $10 \mathrm{Gbit} / \mathrm{s}$ transmission speed; the spectral efficiency is in this case improved from $0.1 \mathrm{bit} / \mathrm{s} / \mathrm{Hz}$ to $0.1333 \mathrm{bit} / \mathrm{s} / \mathrm{Hz}$. Due to a higher modulation frequency, the optical power spectral density is broader, which results in shorter optical 
pulses and stronger influence of CD and ASE noise on the signal quality. This leads to greater degradation of the optical signal, which emerges as a larger standard deviation for " 0 " and " 1 " levels.

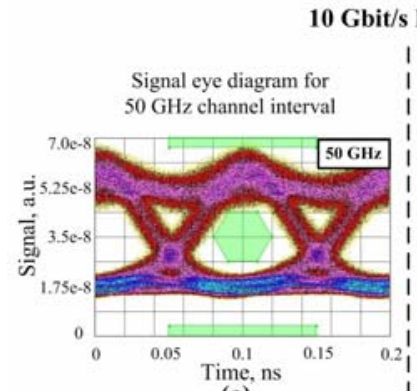

(a)

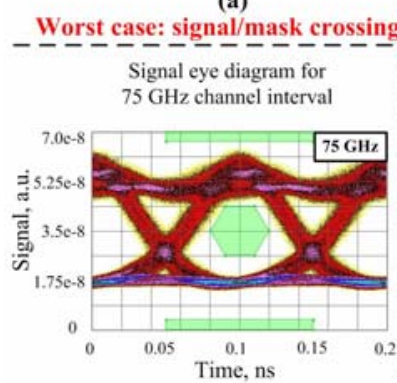

(b)

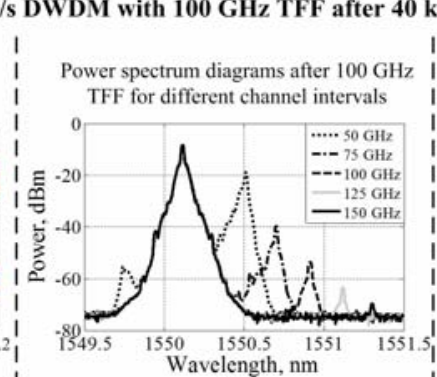

(f)

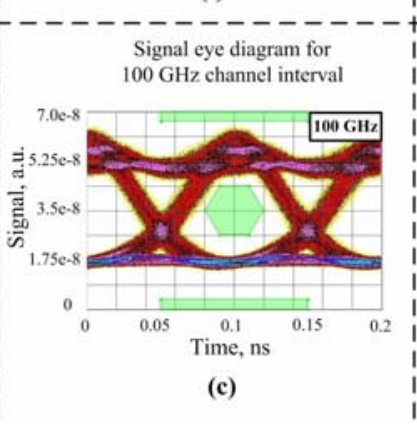

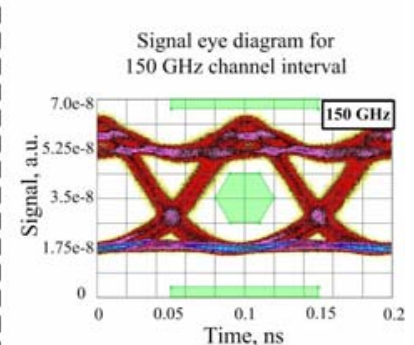

(e)

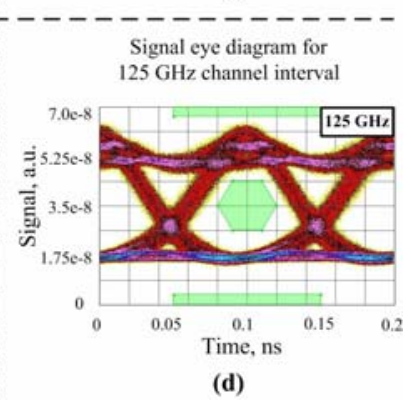

Fig. 6. Eye diagrams $(a-e)$ and optical power spectral densities $(f)$ of $10 \mathrm{Gbit} / \mathrm{s}$ DWDM system realized with $100 \mathrm{GHz}$ TFF after $40 \mathrm{~km}$ of SSMF for different channel intervals (shown in insets).

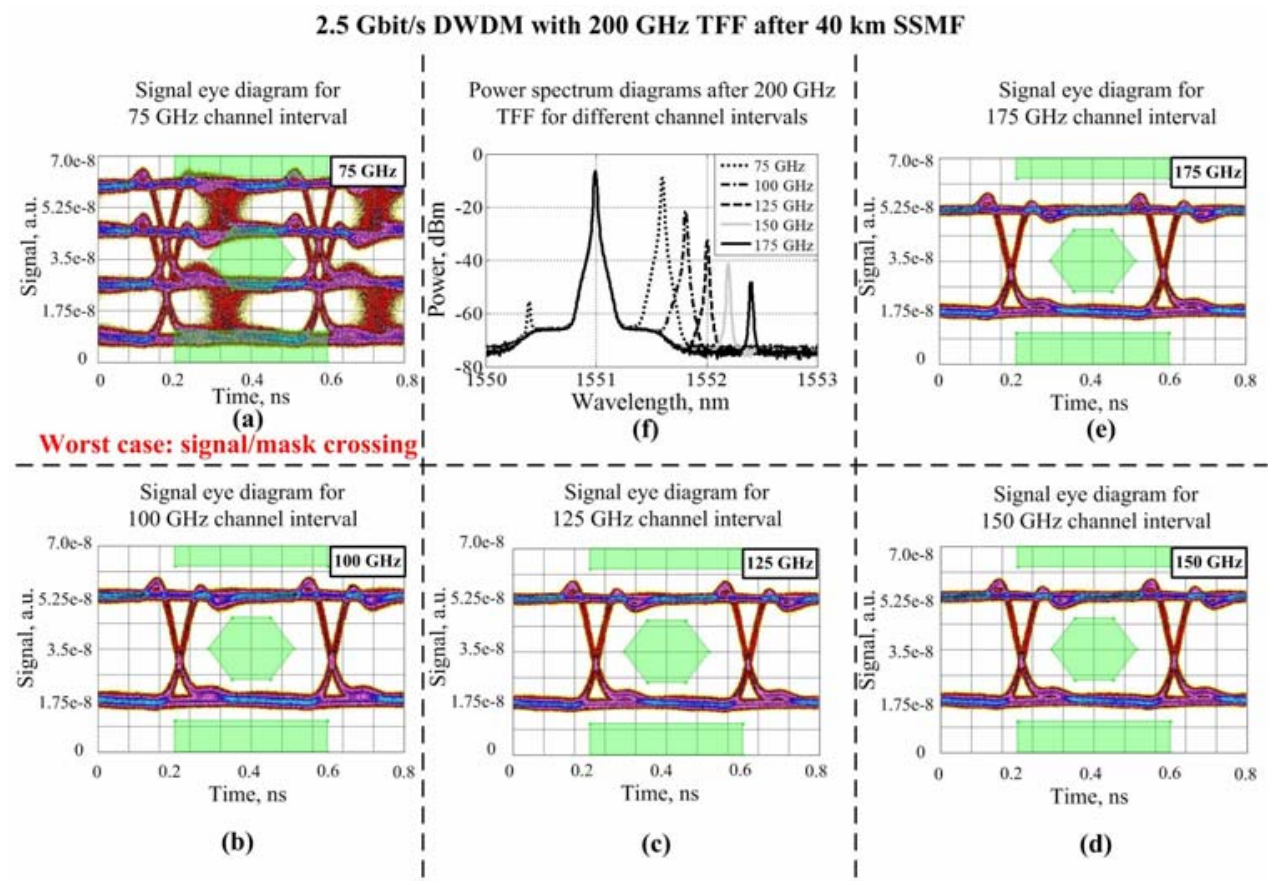

Fig.7. Eye diagrams $(a-e)$ and optical power spectral densities $(f)$ of $2.5 \mathrm{Gbit} / \mathrm{s}$ DWDM system realized with $200 \mathrm{GHz}$ TFF after $40 \mathrm{~km}$ of SSMF for different channel intervals (shown in insets). 


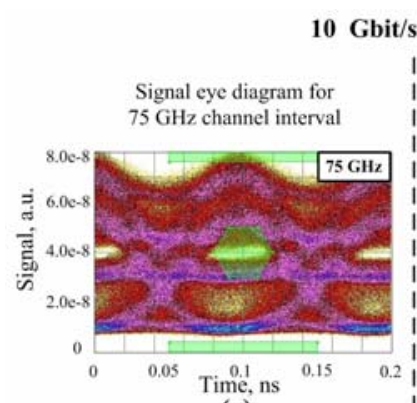

(a)

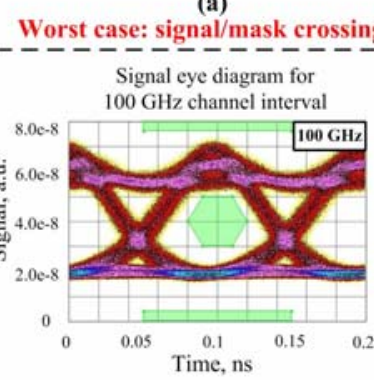

(b)

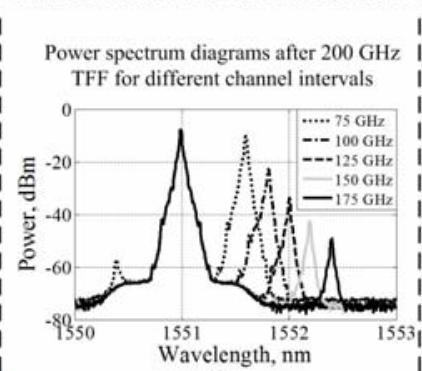

(f)

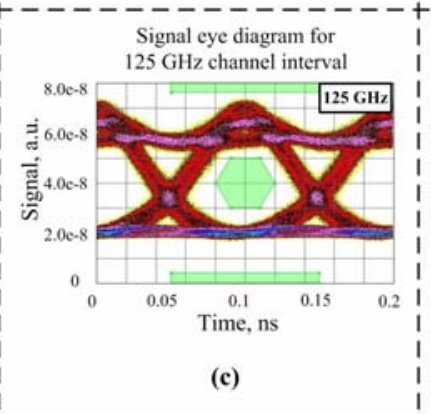

Signal eye diagram for $175 \mathrm{GHz}$ channel interval

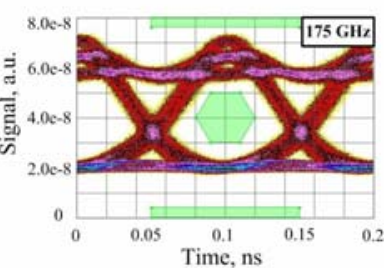

(e)

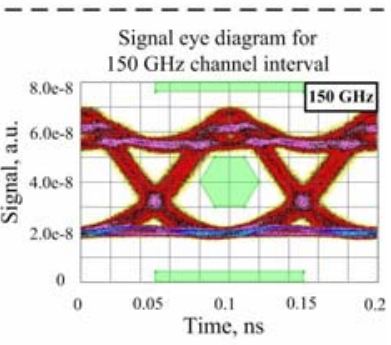

(d)

Fig.8. Eye diagrams $(a-e)$ and optical power spectral densities $(f)$ of a $10 \mathrm{Gbit} / \mathrm{s}$ DWDM system with $200 \mathrm{GHz}$ TFF after $40 \mathrm{~km}$ of SSMF for different channel intervals (shown in the insets).

Figures 7 and 8 show the eye diagrams and optical power spectral densities of $2.5 \mathrm{Gbit} / \mathrm{s}$ and $10 \mathrm{Gbit} / \mathrm{s}$ DWDM systems realized with $200 \mathrm{GHz}$ TFF (amplitude transfer function is shown in Fig. $3 b$ ) after $40 \mathrm{~km}$ of SSMF for different channel intervals from $75 \mathrm{GHz}$ to $175 \mathrm{GHz}$ with $25 \mathrm{GHz}$ ( $0.2 \mathrm{~nm}$ in wavelength range) step.

As can be seen from Figs. 7, 8, a $100 \mathrm{GHz}$ channel interval is sufficient to ensure an appropriate BER value for a DWDM (200 GHz TFF) system's performance. Figures $7 a$ and $8 a$ clearly show that a $75 \mathrm{GHz}$ channel interval is insufficient to suppress the adjacent channel's power level (i.e. both the signals are detected). To ensure appropriate signal detection, the channel interval was raised to $100 \mathrm{GHz}$, owing to which the power level of adjacent channel was suppressed (see Figs. $7 f$ and Fig. $8 f$ ). Since there is no signal and mask crossing, the signal quality corresponds to the BER limit defined by ITU. Thus, the spectral efficiency of $10 \mathrm{Gbit} / \mathrm{s}$ DWDM systems with $200 \mathrm{GHz}$ TFF has risen from $0.05 \mathrm{bit} / \mathrm{s} / \mathrm{Hz}$ to $0.1 \mathrm{bit} / \mathrm{s} / \mathrm{Hz}$.

\section{CONCLUSIONS}

We have realized a DWDM transmission system that includes TFFs with $100 \mathrm{GHz}$ and $200 \mathrm{GHz}$ FWHM bandwidth and measured the eye diagrams and optical power spectral densities for different channel intervals. From the measurement results we found the minimum channel interval for each of the optical filters to ensure reliable data transmission, and therefore were able to increase the spectral efficiency of the whole DWDM system. The main conclusions from our investigations are as follows. 
- In the measurements according to our method for testing passive devices an ASE light source and an OSA (to perform sweeping) were employed. The method has been proved to be suitable for this purpose and allows the central wavelength, bandwidth, insertion loss and adjacent channel isolation to be determined from the obtained functions of amplitude transfer. The $100 \mathrm{GHz}$ and $200 \mathrm{GHz}$ TFF devices used for the measurements were made for the $33^{\text {rd }}$ $(1550.92 \mathrm{~nm}$ or $193.3 \mathrm{THz})$ and the $34^{\text {th }}(1550.12$ or $193.4 \mathrm{THz})$ channels, respectively, of the ITU-T frequency grid.

- In $2.5 \mathrm{Gbit} / \mathrm{s}$ and $10 \mathrm{Gbit} / \mathrm{s}$ DWDM systems with $100 \mathrm{GHz}$ TFF an undesirable nonlinear interaction was observed for a $50 \mathrm{GHz}$ channel interval. To reduce it, the channel interval was increased to $75 \mathrm{GHz}$, which proved to be sufficient to ensure appropriate BER value for the system's performance.

- In the same DWDM systems with $200 \mathrm{GHz}$ TFF the undesirable nonlinear interaction and detection of both signals were observed for a $75 \mathrm{GHz}$ channel interval. To achieve single-channel detection (with ITU-defined BER $<10^{-12}$ ) and suppression of the adjacent channel's power level this interval was increased to $100 \mathrm{GHz}$.

- The spectral efficiency of the $10 \mathrm{Gbit} / \mathrm{s}$ DWDM system with $100 \mathrm{GHz}$ TFF was raised from $0.1 \mathrm{bit} / \mathrm{s} / \mathrm{Hz}$ to $0.1333 \mathrm{bit} / \mathrm{s} / \mathrm{Hz}$, and of the $10 \mathrm{Gbit} / \mathrm{s}$ DWDM system with $200 \mathrm{GHz}$ TFF - from $0.05 \mathrm{bit} / \mathrm{s} / \mathrm{Hz}$ to $0.1 \mathrm{bit} / \mathrm{s} / \mathrm{Hz}$.

\section{Acknowledgment}

This work has been supported by the European Regional Development Fund in Latvia within the project Nr. 2010/0270/2DP/2.1.1.1.0/10/APIA/VIAA/002 and by the European Social Fund within the project ,, Support for the implementation of doctoral studies at the Riga Technical University”.

\section{REFERENCES}

1. Kaur, G., Singh, M.L., \& Patterh, M.S. (2010). Impact of fibre nonlinearities in optical DWDM transmission systems at different data rates. Optics, 121, 2166-2171.

2. Hohlfeld, D., \& Zappe, H. (2004). An all-dielectric tunable optical filter based on the thermo-optic effect. J. Opt. A: Pure Appl. Opt., 6, 504-511.

3. Ozolinšš, O., Bobrovs, V., \& Ivanovs, G. (2010). Efficient wavelength filters for DWDM systems. Latv. J. Phys. Tec. Sci., 47(6), 13-24.

4. Ozolinšš, O., \& Ivanovs, G. (2010). Evaluation of band-pass filter influence on the NRZ signal in HDWDM Systems. Electronics and Electrical Engineering, 100 (4), 65-68.

5. Shen, W., Sun, X., Zhang, Y., Luo, Z., Liu, X., \& Gu, P. (2009). Narrow band filters in both transmission and reflection with metal/dielectric thin films. Optics Communications, 282, 242-246.

6. Venghaus, H. (2006). Wavelength Filters in Fibre Optics. Berlin: Springer, p. 454.

7. Sumriddetchkajorn, S., \& Chaitavon, K. (2007). $1 * \mathrm{~N}$ add-drop filter structures using one dense wavelength division multiplexing thin-film filter. Optics Communications, 280, 33-38.

8. Ivanovs, G.., Bobrovs, V., Ozoliņ̌š, O., \& Poriņ̌š, J. (2010). Realization of HDWDM Transmission System. International J. of Physical Sciences, 5 (5), 452-458.

9. Dutta, A. K., Dutta, N. K., \& Fujiwara, M. (2003). WDM TECHNOLOGIES: Passive Optical Components. USA: Academic Press, p. 551.

10. Macleod, H.A. (2001). Thin-Film Optical Filters. Third edition. Bristol: J.W. Arrowsmith Ltd. Institute of Physics Publishing, p. 641. 
11. Audet, F. (2003). Broadband sources enhance optical-spectrum analysers. Laser Focus World, 39 (2), 10-12.

12. Ozoliņš, O., Bobrovs, V., \& Ivanovs, G.. (2010). Investigation into the potentialities of quasi-rectangular optical filters in HDWDM systems. Latv. J. Phys. Tec. Sci., 47 (1), 17-29.

\section{DWDM PĀRRAIDES REALIZĀCIJA AR PLĀNO KĀRTIN̦U FILTRU TEHNOLOGIJU}

O. Ozoliņš, V. Bobrovs, Ģ. Ivanovs

$$
\text { Kopsavilkums }
$$

Autori ir izveidojuši augsta blīvuma vil̦ngarumdales blīvēšanas (DWDM) pārraides sistēmu ar diviem plāno kārtiņu filtriem (FWHM joslas platums $100 \mathrm{GHz}$ un $200 \mathrm{GHz}$ ), lai novērtētu minimālo kanālu intervālu, pie kura ir pietiekami mazs kḷūdu koeficients. Tāpēc veikti detalizēti pētījumi par TFF ietekmi uz optisko signālu de-multipleksēšanu DWDM sistēmās. Novērtējums tika veikts ar uztvertā signāla acu diagrammas un optiskās jaudas spektrālā blīvuma mērījumiem. No mērījumu rezultātiem esam atraduši minimālos kanālu intervālus noteiktiem optiskajiem filtriem, lai nodrošinātu drošu datu pārraidi un līdz ar to palielinātu sistēmas kopējo spektrālo efektivitāti. No rezultātiem redzams, ka DWDM pārraides sistēmai ar $100 \mathrm{GHz}$ TFF pietiekošu veiktspēju nodrošina $75 \mathrm{GHz}$ kanālu intervāls pie $10 \mathrm{Gbit} / \mathrm{s}$ datu pārraides ātruma un līdz ar to tiek palielināta spektrālā efektivitāte no $0.1 \mathrm{bit} / \mathrm{s} / \mathrm{Hz}$ līdz $0.1333 \mathrm{bit} / \mathrm{s} / \mathrm{Hz}$.

09.05.2011 